\title{
POSSIBILITY OF USING LANDSAT SATELLITE RECORDINGS IN VISUALIZATION AND DETECTION OF THERMAL ISLANDS IN THE AREA OF THE CITY VINKOVCI
}

\author{
Ivana Petrinjak ${ }^{1}$, Nikola Kranjčić ${ }^{{ }^{*}}$, Milan Rezo ${ }^{1}$, Bojan Đurin ${ }^{2}$ \\ ${ }^{1}$ University of Zagreb, Faculty of Geotechnical Engineering, Hallerova aleja 7, 42000 Varaždin, Croatia \\ ${ }^{2}$ University North, Department of Civil Engineering, Jurja Križanića 31b, 42000 Varaždin, Croatia \\ *E-mail of corresponding author: nikola.kranjcic@gfv.unizg.hr
}

\begin{abstract}
All satellite data is generated as a record of electromagnetic radiation detected on the satellite sensor. The product of collecting information in remote explorations is a digital satellite record consisting of a pixel network representing the smallest surface that a particular sensor can collect, which is also a spatial resolution of the image. The position of each pixel is determined in the Cartesian coordinate system. To allow the ability to monitor climate change or mitigate the consequences of a natural disaster, the USGS has developed the Earth Explorer tool. USGS (US Geological Institute) provides science on natural hazards endangering life and existence; water, energy, minerals and other natural resources we rely on. This analysis will highlight the ability to use and monitor satellite imagery using the Earth Explorer browser. All satellite images are processed in QGIS. The spatial resolution of the satellite index (NDVI) as a quantitative measure of the state of the vegetation cover was tested on Landsat 8 images in the area of the city of Vinkovci. Highlighted natural disasters are thermal islands, and damage to the forest cover.
\end{abstract}

Keywords: USGS Earth Explorer, Landsat 8, natural disasters, floods, thermal islands.

\begin{tabular}{c}
\hline Received: $24.09 .2019 . /$ Accepted: 16.01.2020. \\
Published online: 10.07.2020. \\
\hline $\begin{array}{c}\text { Original scientific paper } \\
\text { https://oi.org/10.37023/ee.7.1.3 }\end{array}$
\end{tabular}

\section{INTRODUCTION}

Remote Sensing is the process of detecting and monitoring the physical and solid surface area by measuring reflected and emitted radiation at a distance from the targeted areas. Special cameras capture images of Earth from a distance that help researchers "feel" things around Earth. It excludes all activities from recordings, procedures, analyzes, interpretations, and obtains data from data collected through these studies (Lapaine \& Frančula 2015)

Data is obtained from long distance (from several hundred to several thousand kilometres) instruments placed in aircraft or spacecraft. The first aerial photography of the Earth was made in the mid-19th century. In 1858, the Balloon Tournachon made the first recordings to analyze the metropolitan area of Paris, and in 1862, the recordings used in the American Civil War. Massive application of aerial imagery and photointerpretation began in the First and continued in the Second World War. The revolution in remote sensing is the beginning of space photography. The first capture of Earth from space was done in 1959 by the US Explorer, Explorer 6. There are several recording procedures, which are sorted by recording (full size or results), equipment (photographic or electronic), transmission and processes (analogue or digital), number of channels in the spectrum (single or multi-channel), recording view (plane or stereoscopic), use of natural radiation or broadcast with the aircraft (passive or active), usage (for geodetic, cartographic, agrotechnical, meteorological, traffic, military and other needs).

Some specific usage of remote sensing images:

- large forest fires can be mapped from space, which enables monitoring of larger area,

- cloud monitoring to predict the weather or view of the volcano's evacuation and help track storms.

- monitoring the growth of the city and changes in farmland or forests over several years or even de-seeding,

- Ocean Bottom Mapping - Detecting and mapping rough ocean bottom topographies (e.g., huge mountain ranges, deep-sided canyons and "magnetic strip" at the bottom of the ocean).

The beginning of collection usable and more widely available satellite information with applications to various segments of human activity is closely linked to the Landsat mission, which has operated since 1972 to the present. The Landsat program, which established a collaboration between the United States Space Agency (NASA) and the US Geo-logical Survey (USGS), consist of a series of satellite missions (Landsat 1 - Landsat 8). They have been continuously upgraded to this day, and today they are one of the most significant sources of global retrospective data (Gutman \& Masek 2012). The use of satellite Landsat imagery has been particularly increased in last few years since the archives of the recordings are made public on the USGS portal. It is 
important to familiarize society with readily available information so that different scientific fields can progress more easily. The most used satellite imagery sources are USGS Earth Explorer, Landviewer, Copernicus Open Access Hub, Sentinel Hub, Nasa Earthdata Search, Remote Pixel, INPE Image Catalogue (Top free satellite imagery sources in 2019).

This paper seeks to emphasize the issue of natural disasters, followed largely by environmental pollution sources. Furthermore, besides population growth, environmental pollution is also significantly influenced by human activities, whose primary role is meeting the needs of a part of the population, with the most significant impact on the natural environment in the form of greenhouse gases, environmental degradation, increasing wastewater, etc. Therefore, introducing the monitoring of satellite images in order to protect natural resources and enable further growth and development of the planet Earth. Recent advances in remote sensing and technology applications have made it possible to use remote sensing satellite imagery to assess the vulnerability of urban areas to natural disasters such as earthquakes. QuickBird, a high-resolution commercial satellite with a maximum spatial resolution of $0.6 \mathrm{~m}$, successfully launched on October 18, 2001. It acquires optical images of urban areas and enables the identification and assessment of critical areas at which objects are most at risk (developing threat assessments, plans protection). The area of the Republic of Croatia, as part of the Mediterranean-Transasian belt, is characterized by a pronounced seismic activity and in the future, this type of monitoring could be applied in the construction of resilient buildings

\section{LANDSAT MISSION}

Since 1972, Landsat satellites have provided continuous spatial data on Earth's terrestrial surface in order to improve scientific research in order to understand our rapidly changing planet. First Landsat satellites generated a vast amount of new data that improved the mapping of remote areas and geological features along with digital vegetation analysis. Landsat's spatial and spectral resolutions have increased its use for broader societal benefits such as global crop forecasting, forest monitoring, water use, carbon estimates, and as a basis for developing a Google map. Landsat's long-term data record is important resource for monitoring land cover change and land use over a period of more than four decades. A free and open Land-Hour data policy, published in 2008, launched a global-scale survey. Developing analytical and computational capabilities allows solving a complex worldwide problem. Landsat offers real-time monitoring capabilities to help further understand the changing planet Earth. Thus, a unique historical archive was created that stands out for its number of details, quality and the spatiotemporal segment covered. This database continuously provides insight into the visual and scientific features of our planet. The Landsat recording archive is often cited as one of the greatest treasures of humanity, an achievement that brings great benefit to all segments of society (Butcher et al. 2019). Table 1 shows the characteristics of the Landsat missions, where R - Red, G - Green, B - Blue, NIR - Near Infrared, SWIR - Short Wave Infrared, TIR - Thermal Infrared, MID - Mid-Infrared, MS - lower spatial resolution - multispectral, PAN - higher spatial resolution - panchromatic. Early Landsat recordings revealed many errors in modern nautical charts. For example, researchers have seen that reefs, coasts, and islands have been misplaced or omitted entirely in the Chagos Islands (Figure 1; left). Landsat provided information to warn boaters in the region until the revised chart (Figure 1; middle) included the newly discovered Colvocoresses coral reef (fully submerged "Indian Ocean atoll") and the adjusted position of the ring coral reef, Speakers bank. Landsat dated April 2, 2018 (Figure 1; right) shows the current locations of the Colvocoresses, Speakers Bank and Blenheim reefs.
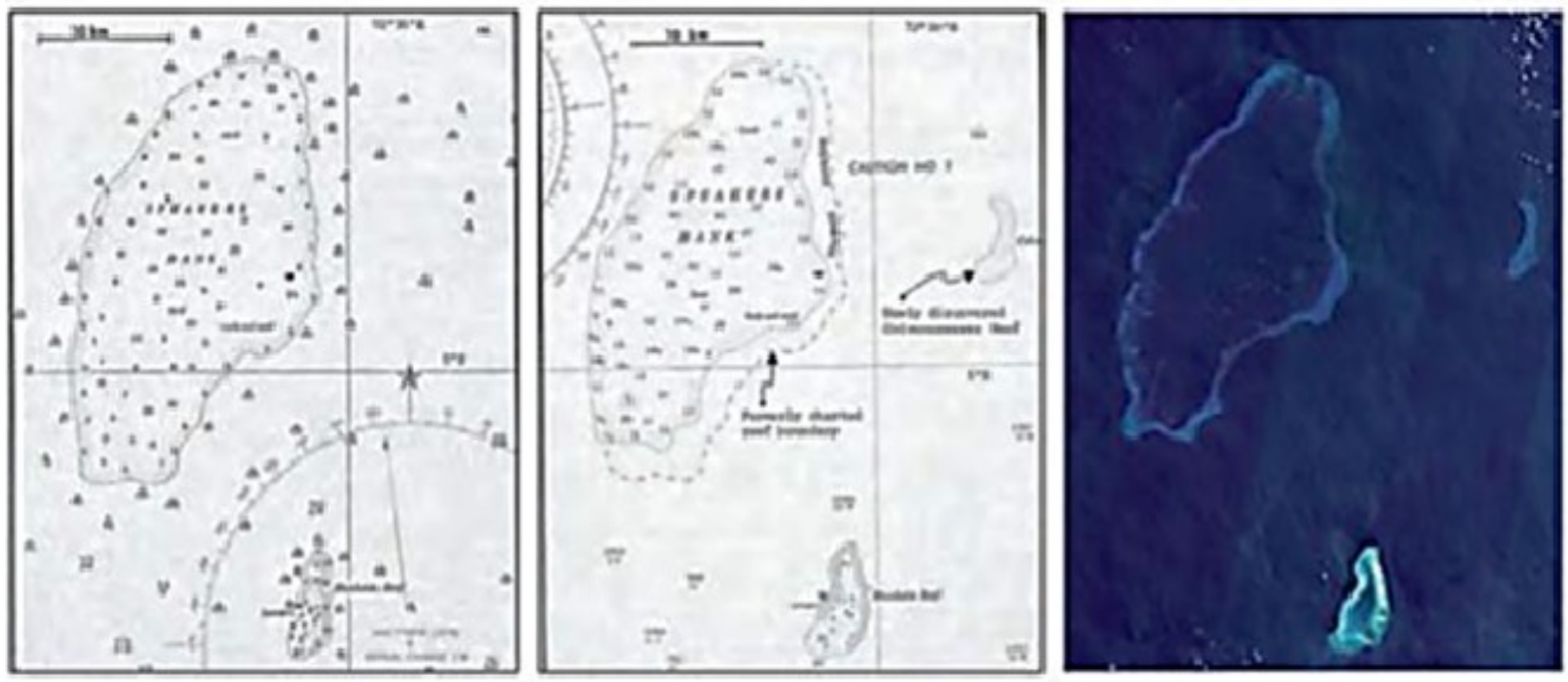

Figure 1. Nautical map and new coral reef in Indian ocean (Butcher et al. 2019) 
Table 1. Characteristics of Landsat missions (Vela et al. 2017)

\begin{tabular}{|c|c|c|c|c|}
\hline Parameters & Landsat 1-3 MSS & Landsat 4-5 TM & Landsat 7 ETM+ & $\begin{array}{l}\text { Landsat } 8 \\
\text { OLI/TIRS }\end{array}$ \\
\hline Mission duration & $\begin{array}{l}1972-1978 \\
1975-1983 \\
1978-1983\end{array}$ & $\begin{array}{l}1982-1993 \\
1984-2013\end{array}$ & 1999 - & $2013-$ \\
\hline Orbit height $(\mathrm{km})$ & 915 & 705 & 705 & 705 \\
\hline Spectral channels & $\mathrm{R}, \mathrm{G}, 2 \mathrm{NIR}$ & $\begin{array}{c}\mathrm{R}, \mathrm{G}, \mathrm{B}, 2 \text { NIR, } \\
\text { MIR, TIR }\end{array}$ & $\begin{array}{l}\text { R, G, B, } 2 \text { NIR, } \\
\text { TIR, MID, PAN }\end{array}$ & $\begin{array}{c}\text { Coastal, R, G, B, } \\
\text { NIR, SWIR-1, } \\
\text { SWIR-2, TIR-1, } \\
\text { TIR-2, PAN }\end{array}$ \\
\hline $\begin{array}{l}\text { Spectral resolution } \\
(\mathrm{m})\end{array}$ & $80 \mathrm{MS}$ & $\begin{array}{c}30 \mathrm{MS} \\
120 \mathrm{TIR}\end{array}$ & $\begin{array}{l}15 \mathrm{PAN} \\
30 \mathrm{MS} \\
60 \mathrm{TIR} \\
\end{array}$ & $\begin{array}{c}15 \mathrm{PAN} \\
30 \mathrm{MS} \\
100 \mathrm{TIR}\end{array}$ \\
\hline $\begin{array}{c}\text { Time resolution (in } \\
\text { days) }\end{array}$ & 18 & 16 & 16 & 16 \\
\hline
\end{tabular}

\subsection{From analogue to digital}

First Landsat satellites (1-3) had a Vidicon return beam (RBV) based on proven television technology and the newly developed multispectral scanner (MSS). MSS was the first space instrument to digitally encode Earth data, to obtain orbital calibration data, and to measure data across multiple spectral channels with sufficient geometric fidelity to allow meaningful comparisons between these channels. Although images can be processed from MSS digital data to perform qualitative analysis such as aerial photographs, the potential for quantitative analysis of satellite data - that is, quantitative remote sensing - has been revolutionary. MSS has quickly proven itself in applications such as vegetation types classification and encouraged the adoption of digital satellite data for Earth observation, leading to the development of more advanced multispectral instruments (Butcher et al. 2019).

This process of digital image processing and statistical data analysis redefined modern passive remote sensing from space. The technical characteristics for a new generation of multispectral scanner instruments have been defined based on application - especially agricultural and geological surveys for the new requirements of Thematic Mapper (TM). The TM instrument could be much more sophisticated, with a resolution of $30 \mathrm{~m}$, seven spectral bands and continued on-board calibration. Optimally, the next mission would include two coverage satellites lasting eight days. Landsat 4 and 5 were launched in 1982 and 1984 respectively. With each new generation of sensors, resulted in the need of the Landsat community users for improved spatial and radiometric resolution, spectral and temporal coverage, geolocation, and calibration. Landsat 7 was launched in 1999 with an enhanced Thematic Plus $(\mathrm{ETM}+)$ map that added a panchromatic band (band) for increased spatial resolution and increased thermal resolution from $120 \mathrm{~m}$ to $60 \mathrm{~m}$. Landsat 8 was launched for shooting about 750 scenes a day, an increase of about 450 scenes a day on Landsat 7 Earth observation, leading to the development of more advanced multispectral instruments (Butcher et al. 2019).

\subsection{Landsat 8 data}

In collaboration with NASA (National Aeronautics and Space Administration), US Department of the Interior, USGS (United States Geological Survey), Orbital Science Corporation and Ball Aerospace \& Technologies, and NASA's Goddard Centre for space flight, on 11th February 2013 successfully launched the Landsat 8 satellite at Vandenberg Air Force Base. The original name of the mission (satellite) was LDCM (Landsat Data Continuity Mission), which was changed to Landsat 8 after NASA conducted its satellite testing and verification on May 30 , 2013 and hand over operations management to the USGS. The orbit of Landsat 8 is defined in relation to the Worldwide Reference System5 (WRS-2), synchronized with the Sun and is at an altitude of $7056 \mathrm{~km}$. The inclination of the orbit is $98.2^{\circ}$. The satellite traverses Earth in 98.9 minutes, and the time of crossing the equator is 10:00 UTC +/- 15 minutes. These orbit characteristics allow the Landsat 8 satellite to cover the entire globe (except for smaller polar regions) every 16 days (EROS 2013). The Landsat 8 satellite (Figure 2) has two sensors for collecting data, for capturing satellite images. The first sensor is the OLI (Operational Land Imager), it has 9 spectral channels, comprising the visible, Near Infrared (NIR) and short wavelength infrared (SWIR) part of the spectrum. One of these nine channels is panchromatic. The second sensor is TIRS and has 2 spectral channels that comprise the Long Wavelength Infrared (LWIR). Table 2 shows the characteristics of the sensors listed. 


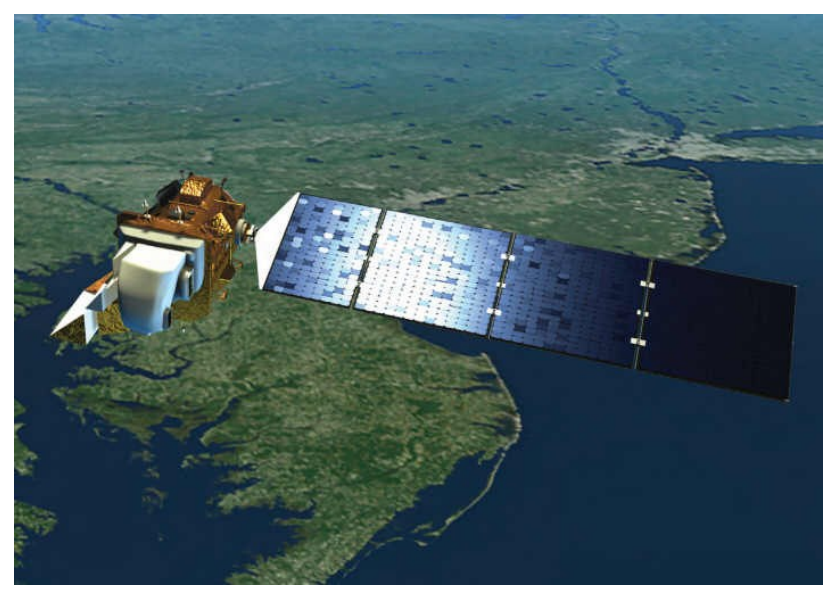

Figure 2. Landsat 8 satellite in orbit (Francica 2013)

Table 2. Characteristics of OLI \& TIRS sensors (EROS 2013)

\begin{tabular}{|c|c|c|c|c|c|}
\hline Sensor & $\begin{array}{c}\text { Channel } \\
\text { [number] }\end{array}$ & $\begin{array}{c}\text { Wavelength } \\
{[\mu]}\end{array}$ & $\begin{array}{c}\text { Spatial } \\
\text { resolution [m] }\end{array}$ & Description & Channel name \\
\hline \multirow{9}{*}{ OLI } & 1 & $0,43-0,45$ & 30 & visible & coastal blue \\
\hline & 2 & $0,45-0,51$ & 30 & visible & blue \\
\hline & 3 & $0,53-0,59$ & 30 & visible & green \\
\hline & 4 & $0,64-0,67$ & 30 & visible & red \\
\hline & 5 & $0,85-0,88$ & 30 & NIR & near infrared \\
\hline & 6 & $1,57-1,65$ & 30 & SWIR & $\begin{array}{c}\text { short } \\
\text { wavelength } \\
\text { infrared - } 1 \\
\end{array}$ \\
\hline & 7 & $2,11-2,29$ & 30 & SWIR & $\begin{array}{c}\text { short } \\
\text { wavelength } \\
\text { infrared - } 2\end{array}$ \\
\hline & 8 & $0,50-0,68$ & 15 & panchromatic & panchromatic \\
\hline & 9 & $1,36-1,38$ & 30 & Cirrus & Cirus \\
\hline \multirow{2}{*}{ TIRS } & 10 & $10,60-11,19$ & 100 & LWIR & $\begin{array}{l}\text { long } \\
\text { wavelength } \\
\text { infrared - } 1\end{array}$ \\
\hline & 11 & $11,50-12,51$ & 100 & LWIR & $\begin{array}{c}\text { long } \\
\text { wavelength } \\
\text { infrared - } 2\end{array}$ \\
\hline
\end{tabular}

\section{MATERIALS AND METHODS}

\subsection{Research area}

The survey was conducted in the Vinkovci area (Figure 3), based on the 2018 Landsat 8 (30 m) satellite imagery. The town of Vinkovci is in the northeast of Croatia between the rivers Danube and Sava, on the river Bosut. They are one from five cities in Vukovarsko-Srijemska County.

The area of the town includes two settlements: Vinkovci and Mirkovce. It is surrounded by seven municipalities: Jarmina, Markušica, Nuštar, Stari Jankovci, Privlaka, Andrijaševci and Ivankovo. It is located at $78-125 \mathrm{~m}$ above sea level and the total area of the city is $102805 \mathrm{ha}$. The surroundings of the countryside are rich in fertile soil. The city is located in an important traffic-geographical area through which international traffic routes pass. Due to its geographic location, it is characterized by a mild continental climate with moderate rainfall throughout the year. Summers are sunny and hot and winters cold with snow. In June 2014, the City of Vinkovci signed a contract with the Institute for Tourism of Zagreb to develop a Master Plan for Tourism Development of the City of Vinkovci. The plan itself will be followed by the redevelopment of cities, the improvement of tourism, the opening of new recreational areas, parks, etc (Boranić Živoder et al. 2015). Decision-makers with insight into the research area of the "Thermal Islands" by using existing technology can see what the temperatures are like in individual cities, in which way the city's construction will be increased, thereby reducing green spaces. Croatian cities have not yet made a major step forward in this regard. Four major cities in Croatia - Zagreb, Rijeka, Osijek and Split - have no empirical research on thermal islands in their urban centres, neither on the relationship between 
mortality and high temperatures. Timely responses can ensure the preservation of existing green spaces and encourage the creation of "Green Networks", which directly affects the improvement of the quality of life of citizens.

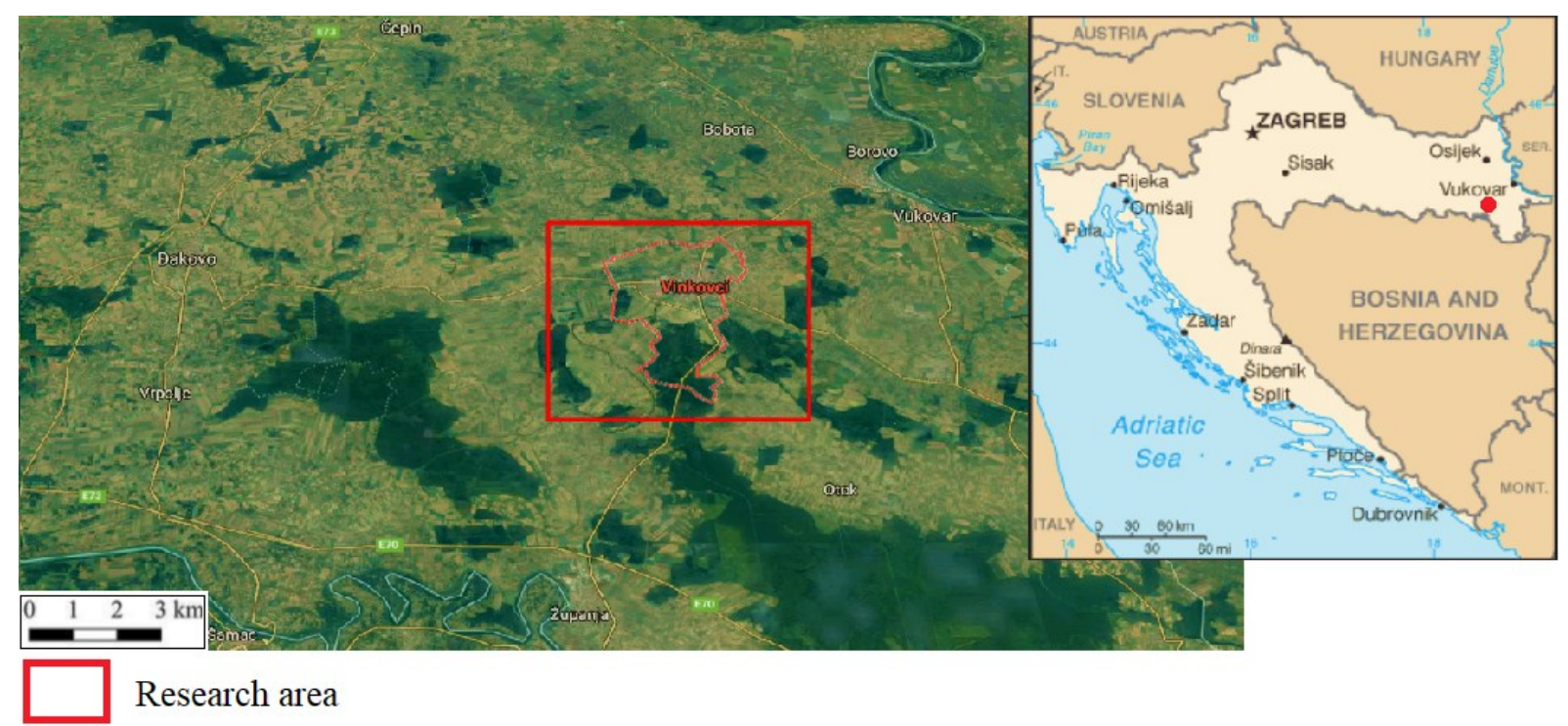

Figure 3. Research area - city Vinkovci

\subsection{Thermal island}

According to the 2018 meteorological records, we can conclude that winter is late and over, and summer is hot and short. In Table 3 and Table 4 the temperatures for March and August can be seen. Table 4 shows the temperatures that in the summer have the greatest impact on the cities where the "heat island" occurs. The thermal island is an area of significantly higher air temperature in relation to the environment, which occurs primarily in cities (Figure 4). As heat islands contribute to the greenhouse gas effect, there is also an impact on global warming, leading to global climate change. This ends in one circular cycle (Agency 2008).

Table 3 Temperature for March 2018 (AccuWeather 2019)

\begin{tabular}{|c|c|c|c|}
\hline Date & $\begin{array}{c}\text { THU } \\
01.03 .\end{array}$ & $\begin{array}{c}\text { FRI } \\
02.03 .\end{array}$ & $\begin{array}{c}\text { SAT } \\
03.03\end{array}$ \\
\hline $\begin{array}{c}\text { Recorded } \\
\text { temperature } \\
{\left[{ }^{\circ} \mathrm{C}\right]}\end{array}$ & $-6^{\circ} /-19^{\circ}$ & $-1 \%-7^{\circ}$ & $-1^{\circ} / 3^{\circ}$ \\
\hline $\begin{array}{c}\text { Average } \\
\text { temperature } \\
{\left[{ }^{\circ} \mathrm{C}\right]}\end{array}$ & $8^{\circ} / 1^{\circ}$ & $9^{\circ} /-1$ & $\circ 9^{\circ} / 1^{\circ}$ \\
\hline
\end{tabular}

Table 4 Temperature for August 2018 (AccuWeather 2019)

\begin{tabular}{|c|c|c|c|c|c|c|c|}
\hline Date & SUN 08.12 & $\begin{array}{c}\text { MON } \\
08.13\end{array}$ & TUE 08.14 & $\begin{array}{c}\text { WED } \\
08.15\end{array}$ & $\begin{array}{c}\text { THU } \\
08.16\end{array}$ & FRI 08.17 & SAT 08.18 \\
\hline $\begin{array}{c}\text { Recorded } \\
\text { temperature } \\
{\left[{ }^{\circ} \mathrm{C}\right]}\end{array}$ & $30^{\circ} / 17^{\circ}$ & $33^{\circ} / 17^{\circ}$ & $33^{\circ} / 18^{\circ}$ & $29^{\circ} / 16^{\circ}$ & $29^{\circ} / 15^{\circ}$ & $32^{\circ} / 15^{\circ}$ & $33^{\circ} / 17^{\circ}$ \\
\hline $\begin{array}{c}\text { Average } \\
\text { temperature } \\
{\left[{ }^{\circ} \mathrm{C}\right]}\end{array}$ & $28^{\circ} / 15^{\circ}$ & $28^{\circ} / 15^{\circ}$ & $28^{\circ} / 15^{\circ}$ & $28^{\circ} / 14^{\circ}$ & $28^{\circ} / 14^{\circ}$ & $28^{\circ} / 14^{\circ}$ & $28^{\circ} / 14^{\circ}$ \\
\hline
\end{tabular}




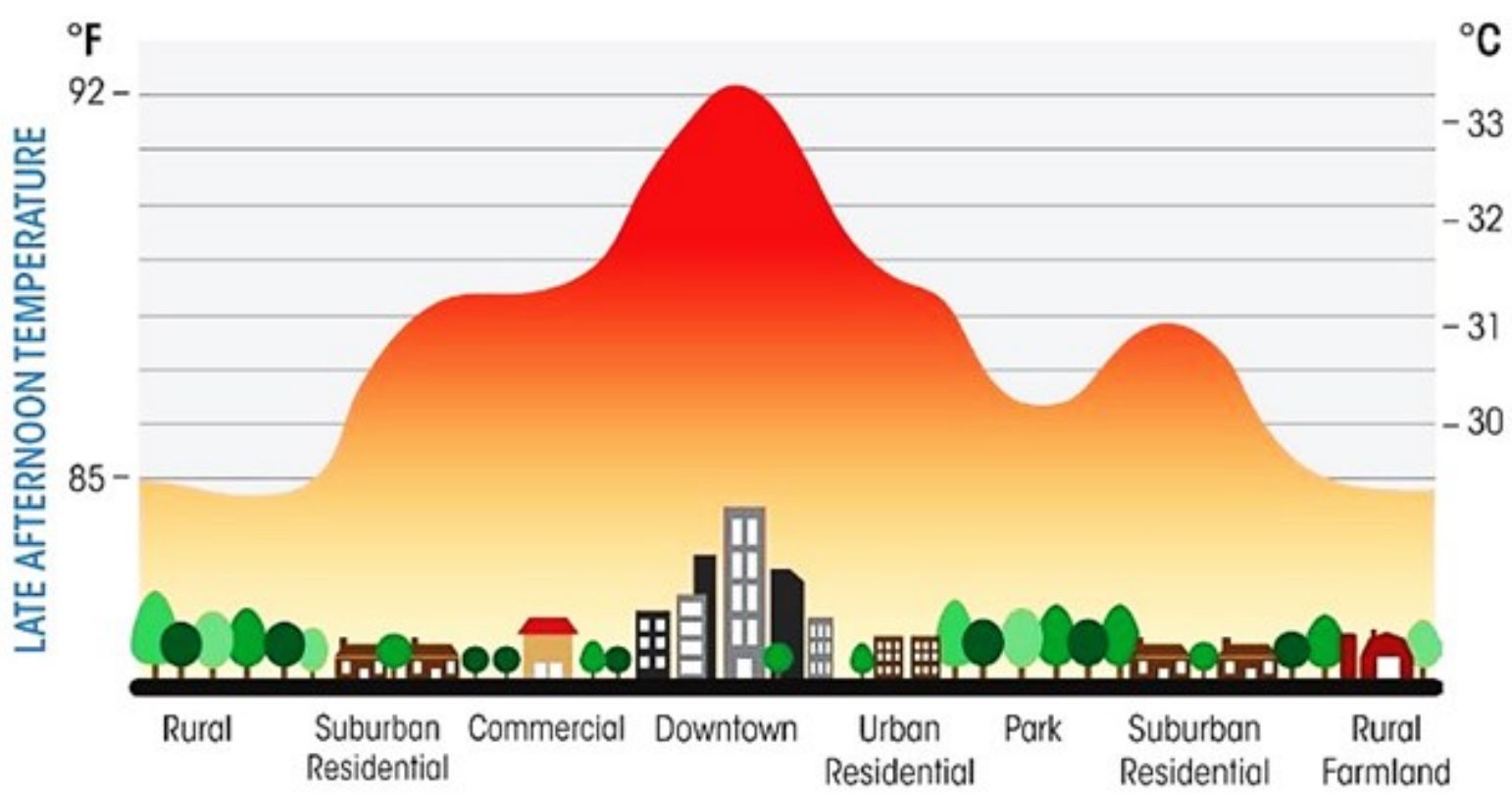

Figure 4. City thermal island profile (measured late afternoon temperature) (SkySpace 2019)

Thermal inland reduces the appearance of weak tornadoes and prolongs the cultivation of plants, but most impacts are negative:

- Increased electricity consumption

- Increased emission of greenhouse gasses

- Impact on human health

- Impact on water quality

The temperature difference in colder seasons can be as high as $10{ }^{\circ} \mathrm{C}$. It is caused by the higher density of residential buildings, the release of heat by the consumption of fossil fuels, traffic and the reduction of natural ventilation. Nowadays on Earth, every city is accompanied by the appearance of heat islands, but the extent of extreme heat de-pends on several factors such as climatic conditions, prevailing winds, type of terrain, type of construction, size of the city. The larger the city, the wider the thermal island. Large cities, such as Paris, London, or Tokyo, have several degrees higher temperatures than the surrounding area, with a tendency to increase as cities expand.

The problem occurs with building materials that do not have a good reflection ability, i.e. they absorb more energy from the Sun, and thus it retains and heats the surface. The increase in temperature is also affected by the height of the buildings and layout, and is usually such that the large amount of heat absorbed during the day is retained and the surfaces are cooled more slowly at night. Another effect in buildings is the blocking of wind, which also prevents cooling, i.e. the reduction of temperatures on building surfaces. Croatian cities have not yet made a major step forward in this regard. According to the surveys con-ducted so far in the Republic of Croatia, none of the surveys concerned thermal islands, i.e. the administrations in Zagreb, Rijeka, Osijek and Split do not have any recorded data on high temperatures in their urban centres. The City of Rijeka recognized this problem and envisaged the erection of a Delta park in the city centre by the Master Urban Plan, which will reduce the effect of the thermal island in the centre and at the same time provide citizens with shelter during the summer heat. In order to calculate the surface temperature, it is necessary to reclassify the (emissivity) classification. The value specified in Table 5 is entered under the ID for each class assigned during the classification. Also, calculating the sur-face temperature, the expression 1.

Table 5. Emissivity values for specific land use

\begin{tabular}{|c|c|}
\hline Land use & Emissivity \\
\hline Water & 0.98 \\
\hline Build-up & 0.94 \\
\hline Vegetation & 0.98 \\
\hline Arable land & 0.93 \\
\hline
\end{tabular}


The surface temperature values for a given area are calculated by the following expression:

$$
\mathrm{T}=\mathrm{T}_{\mathrm{b}} /\left[1+\left(\lambda * \mathrm{~T}_{\mathrm{b}} / \mathrm{c}_{2}\right) * \ln (\mathrm{e})\right]
$$

where:

$\mathrm{T}_{\mathrm{b}}=$ At-Satellite Brightness Temperature

$\lambda=$ wavelength

$\mathrm{c}_{2}=\mathrm{h} * \mathrm{c} / \mathrm{s}=1.4388 * 10-2 \mathrm{c} 2=\mathrm{h} * \mathrm{c} / \mathrm{s}=1.4388 * 10-2 \mathrm{~m} \mathrm{~K}=14388 \mu \mathrm{m} \mathrm{K}$

$\mathrm{h}=$ Planck's constant $=6.626 * 10-346.626 * 10-34 \mathrm{~J} \mathrm{~s}$

$\mathrm{s}=$ Boltzmann constant $=1.38 * 10-231.38 * 10-23 \mathrm{~J} / \mathrm{K}$

$\mathrm{c}=$ speed of light $=2.998 * 1082.998 * 108 \mathrm{~m} / \mathrm{s}$.

The emission wavelengths for the Landsat class are listed in Table 6.

Table 6. The emission wavelength for the Landsat class

\begin{tabular}{|c|c|}
\hline Satellite & Class \\
\hline Landsat $4 ; 5 ; 7$ & 6 \\
\hline Landsat 8 & 10 \\
\hline Landsat 8 & 11 \\
\hline
\end{tabular}

\subsection{Normalized Difference Vegetation Index - NDVI}

In order to determine the density of green areas on a certain surface on the Earth, it is necessary to observe the different wavelengths of visible and near-infrared solar radiation reflected from plants. When sunlight reaches plants, the pigments in the leaves (chlorophylls) absorb visible light $(0.4$ to $0.7 \mu \mathrm{m})$ for use in photosynthesis. The structure of the leaf cells reflects near infrared light $(0.7$ to $1.1 \mu \mathrm{m})$. The more leaves a plant possesses, the greater the influence on wavelengths of light (Figure 5) (Normalized Difference Vegetation Index (NDVI) 2000). Therefore, vegetation in the visible spectrum looks completely different than in the near infrared spectrum. Relative amounts of vegetation are determined on the basis of near-infrared and red wavelengths.

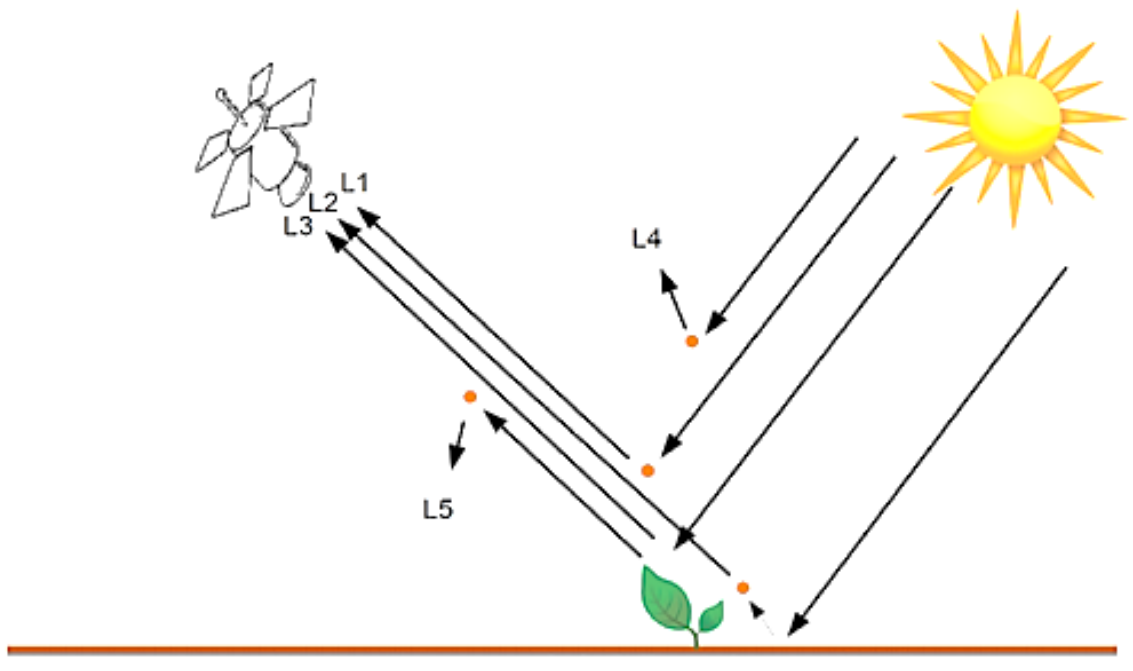

Figure 5. Solar radiation reflection (L1 - atmospheric radiation, L2 - reflected radiation, L3 - ambient radiation, L4; L5 - backscattered radiation) (Rumora et al. 2016)

NDVI's biophysical interpretation is a piece of absorbed photosynthetic radiation activity absorbed from the sur-face (soil). NDVI is affected by a large number of attributes, such as atmospheric conditions, recording scale, vegetation moisture, soil moisture, total vegetation cover, differences in land type, etc. NDVI has a reduced sensitivity to changes in vegetation volume, i.e. with increasing green vegetation change in NDVIs are decreasing more and more. For this reason, at high NDVI values, a small change in NDVI may signify a major change in vegetation. NDVI values (range from -1 to +1 ):

- $\quad(0.1$ or less - Areas covered with rocks, sand or snow

- $(0.2-0.5)$ - Rare vegetation such as shrubs or lawns

- $(0.6-0.9)-$ Dense vegetation that can be found in temperature and tropical forests or crops at peak growth (Huete \& Jackson 1987) 
NDVI can be calculated by Expression 2:

$$
\mathrm{NDVI}=(\mathrm{NIR}-\mathrm{RED}) /(\mathrm{NIR}+\mathrm{RED})
$$

where:

NIR - near infrared channel,

RED - red channel

\section{RESULTS}

\subsection{Classification}

Classification can be described as division or separation. Classification is conducted according to specific principles or criteria depending on the subject and purpose (e.g. alphabetical order, chronological, etc.). In QGIS, the classification of satellite images is used to obtain (extract) thematic information from satellite images in a semiautomatic or automatic manner. There are various procedures used in the classification process. The basic classification is classified into supervised and unsupervised. Only supervised classification was used in this paper. The implementation of supervised classification requires significantly greater interpreter influence as well as prior knowledge of the study area (field experience, data from other sources, etc.). At the beginning of this process, it is necessary to identify the samples and define the number of classes. Then, the interpreter should select representative samples (pixels) for each class (Oluić 2001). Figure 6 shows research area in true colour composition, while Figure 7 shows classification of Vinkovci area.

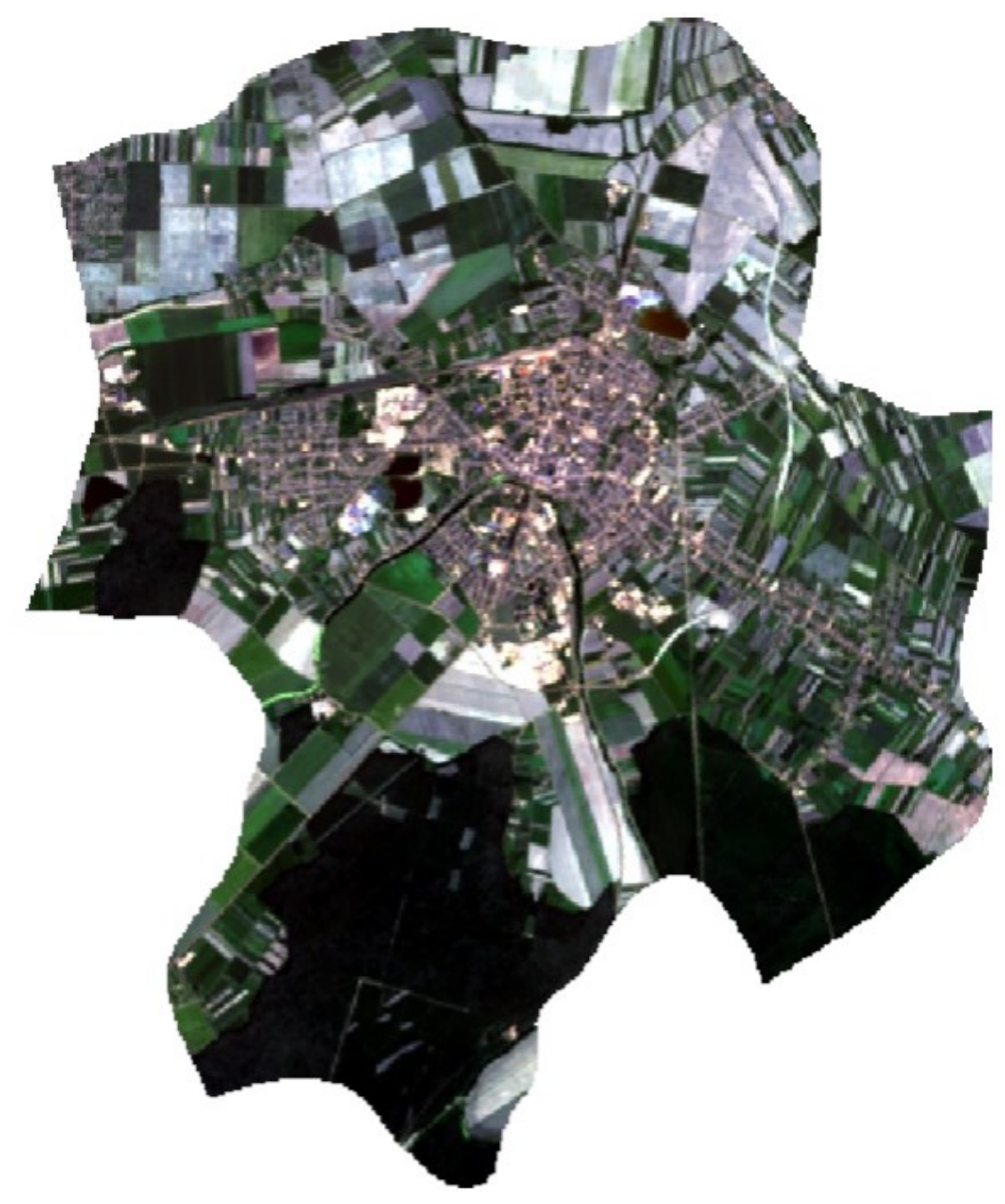

$\begin{array}{llllll}0 & 2 & 4 & 6 & 8 & 10 \mathrm{~km}\end{array}$

Figure 6. True colour composition view of Vinkovci 


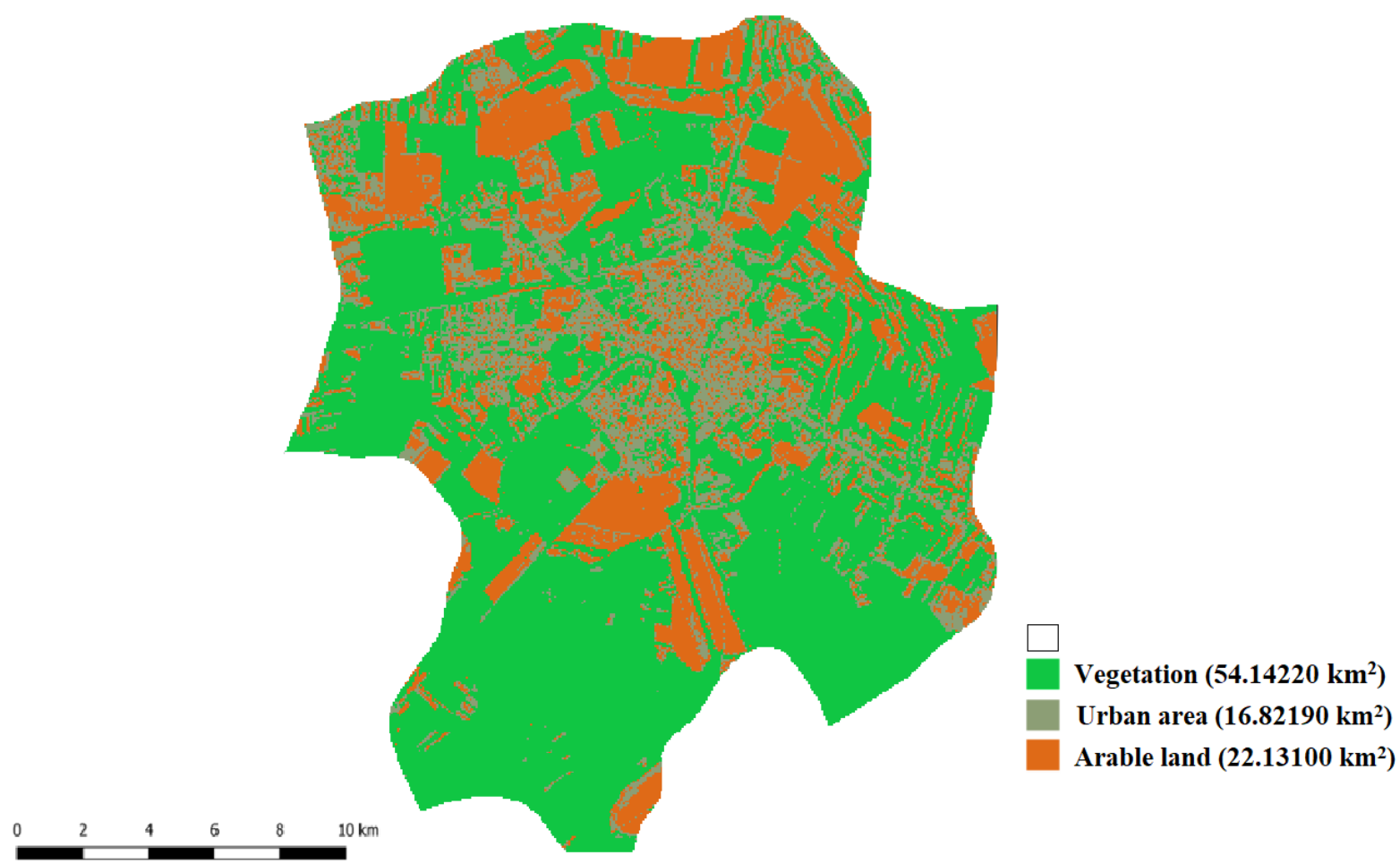

Figure 7. Classification of Vinkovci city area

After the classification of satellite images, the classes are shown polygonal and quantitatively expressed in surface area. In Figure 7, which shows the area of the municipality of Vinkovci, the classes are indicated: vegetation $\left(54.14220 \mathrm{~km}^{2}\right)$, urban area $\left(16.82190 \mathrm{~km}^{2}\right)$, arable land $\left(22.13100 \mathrm{~km}^{2}\right)$. Figure 8 shows the result of the NDVI vegetation index for the cultivated area of the municipalities of Vinkovci for the August. A green colour was used to graphically represent the NDVI analysis. Everything in the grid marked in green indicate that the pixel value is greater than zero (vegetation display). White shows negative values on the grid (low vegetation area or none). According to the colour gradient, it is concluded that the darkest colour indicates the thickest area and the lightest green or white colour less frequently the vegetation area.

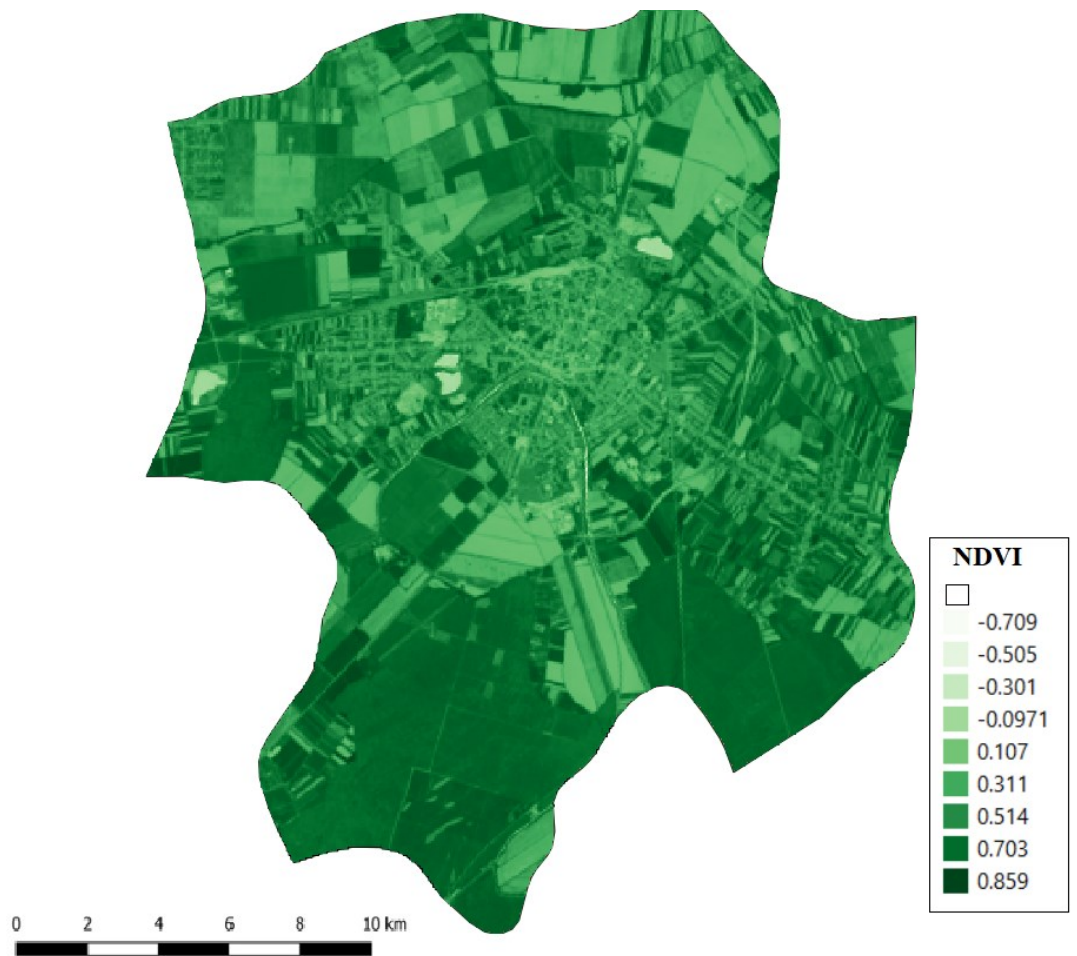

Figure 8. NDVI value for August 2018 
Figure 9 shows the result of determining the surface temperature. The colour spectrum was used to represent the temperature. All shown in red indicates the maximum temperature. Blue indicates the lowest temperature, while other colours indicate the temperature range between min and max. The maximum recorded temperature for August 14 is $42.5^{\circ} \mathrm{C}$ and the minimum recorded temperature is $25.8^{\circ} \mathrm{C}$. With good quality satellite imagery, the temperature can be seen rising closer to the city centre. As we approach the forest, that is, vegetation, we see a significant drop in temperature; the difference is $16.7^{\circ} \mathrm{C}$.

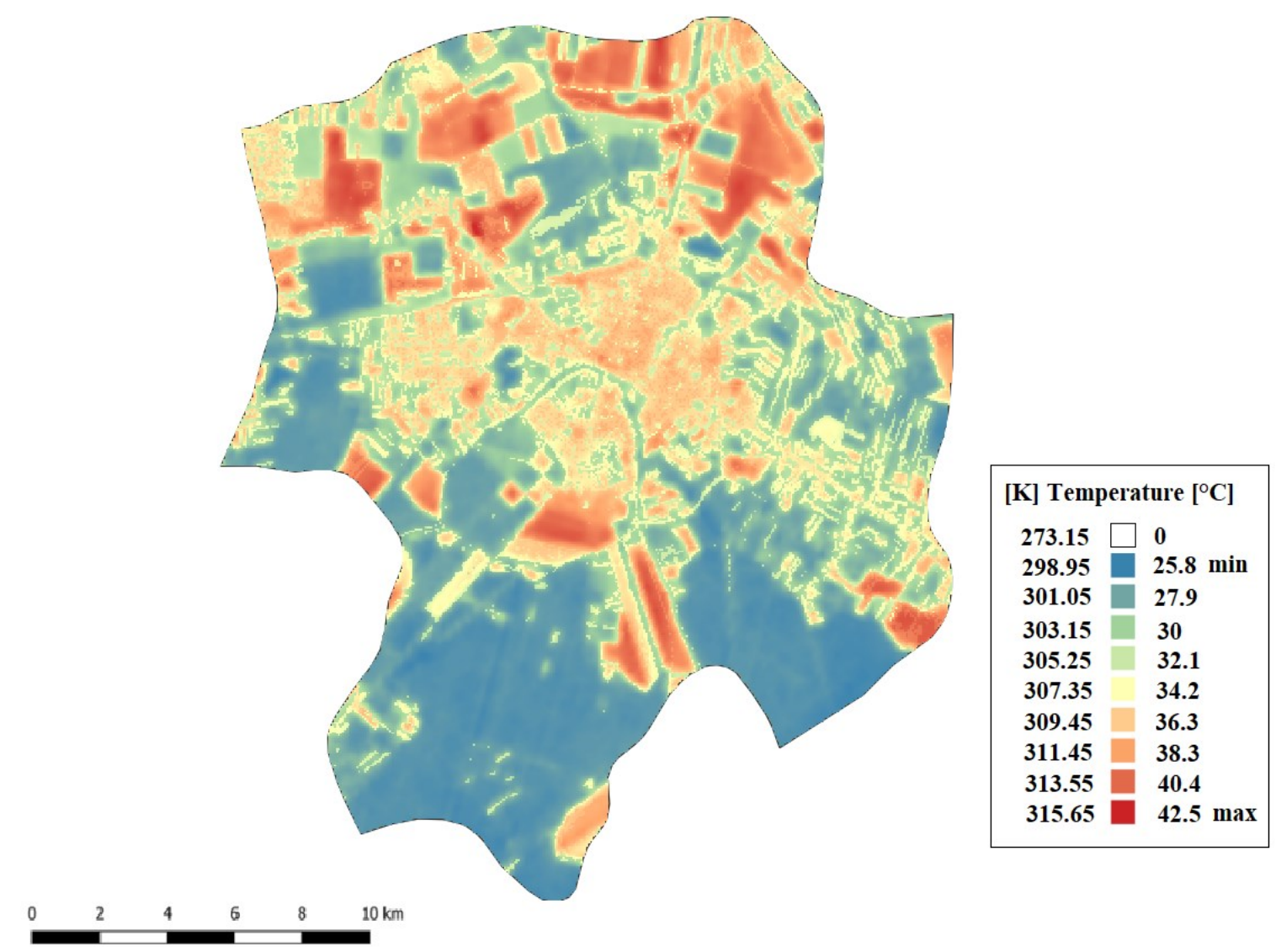

Figure 9. Temperature values in city Vinkovci

\section{CONCLUSION}

With the help of remote sensing techniques, a spatial analysis is carried out, in which the classes of the area of the town of Vinkovci are detected, analysed and interpreted. With this analysis, the simple principle of classification of vegetation areas, primarily green areas, using the NDVI vegetation index and medium-resolution recordings is present-ed. A simple principle, because indexing is a combination of simple arithmetic operations and the necessary channels. Vegetation indices play a significant role in monitoring and detecting vegetation changes in terms of quantity or quality. Their biggest advantage is that they have a low sensitivity to the instability of the correction for the atmosphere and variations in the angle of observation of the satellite. It is important to emphasize that vegetation indices can monitor the disappearance of forest areas (need for afforestation) or agricultural crops.

Emphasis is also placed on elevated temperatures occurring in the city, i.e. in populated areas. With the help of QGIS software, we can very easily calculate the temperature state on a given surface. The physiological sense of the environment rests on the temperature and humidity of the air, the flow of air, the radiation of objects, the admixtures in the air, when the heat islands appear, they merge and cause pressures on human health. The temperature is measured in the shade of a meteorological house and when the thermometer shows 35 degrees, the temperature in the street can rise to 40 degrees, which in addition to other negative effects can have a significant impact on human health. Some strategies for reducing the "heat island" effect that can be applied in cities or heavily populated areas are increasing green spaces, building green parking lots, building green roofs, building cold / reflective roofs, building cold side-walks, educating about the effect of thermal effects the island.

Satellite imagery is the most widespread way of collecting data on large areas today. There is great potential for ap-plication in forestry, which is the basis for the European Union's Global Observation Program, Copernicus. Of particular importance for exploring innovative remote sensing applications is the range of recent Sentinel satellite missions and the availability of imagery for use by the wider scientific community. At present, there is a 
very strong EU initiative aimed at examining different ways of applying and commercializing satellite information, primarily collected from the Sentinel, in different land-based economic sectors (forestry, agriculture, nature protection, water management, etc.). Free satellite imagery can be downloaded with a large amount of new data. The processing of the data is one of the basic prerequisites for obtaining quality results. In the future, interdisciplinarity and the collaboration of all professions from different fields will be important. There is still plenty of room for progress in this field of work. It is possible to work in geo-databases where it would be the source of all information e.g. related to a single location (surface, population, seismicity, temperature, hours of sunshine, soil type, etc.). Also, satellite images can be used in comparison with other images (e.g. Sentinel data) and the ability to compared digital and visual interpretations.

\section{LITERATURE}

Top free satellite imagery sources in 2019 [online], 2019. Earth observing system. Available via: https://eos.com/blog/7-top-free-satellite-imagery-sources-in-2019. Cited 14 May 2019

AccuWeather (2019) Monthly temperatures in Vinkovci [online]. Accuweather. Available via: https:/www.accuweather.com/hr/hr/vinkovci/116156/month/116156?monyr=3/01/2018. Cited 20 Apr 2019

Agency USEP (2008) Urban Heat Island Basics. In: Reducing Urban Heat Islands: Compendium of Strategies.

Boranić Živoder S, Ivandić N, Čorak S, Marković I (2015: Master plan razvoja turizma grada Vinkovaca.

Butcher, G, Owen, L, and Barnes, C, 2019. Landsat: the Cornerstone of Global Land Imaging. GIM International, 44.

EROS U (2013) Landsat 8.

Francica J (2013) Everything You Need to Know about Landsat 8 [online]. Directions Magazine. Available via: https://www.directionsmag.com/article/1662. Cited 14 May 2019

Gutman G, Masek JG (2012) Long-term time series of the Earth's land-surface observations from space. International Journal of Remote Sensing, 33 (15), 4700-4719.

Huete AR, Jackson RD (1987) Suitability of spectral indices for evaluating vegetation characteristics on arid rangelands. Remote Sensing of Environment, 23 (2), 213-232.

Lapaine M, Frančula N (2015) Kartografija i daljinska istraživanja [online]. Available via http://www.kartografija.hr/old_hkd/daljinska.pdf. Cited 19 Apr 2019

Normalized Difference Vegetation Index (NDVI) [online], 2000. NASA Earth observatory.

Oluić M (2001) Snimanje i istraživanje Zemlje iz svemira; Sateliti - Senzori - Primjena. Hrvatska akademija znanosti i umjetnosti.

Rumora L, Medved I, Pilaš I, Medak D (2016) Comparison of Vegetation Index Value Based on Digital Number and Top of Atmosphere Reflectance. Geodetski list, 70 (93) (1), 15.

SkySpace (2019) Urban heat island effect [online]. Sky Space Green Roofs. Available via: http://skyspacegreenroofs.com/wp-content/uploads/2016/10/urban_heat_island_effect2.jpg. Cited 20 Apr 2019

Vela E, Medved I, Miljković V (2017) Geostatistical Analysis of Vegetation Indices in Forest Ecosystem Česma. Geodetski list, 71 (94) (1). 